\title{
Covid-19 en la población pediátrica: ¿menor susceptibilidad y transmisibilidad?
}

\section{Covid-19 in the pediatric population: lower susceptibility and transmissibility?}

\author{
Mirta Mesquita ${ }^{1}$
}

La enfermedad causada por el SARS CoV-2, la Covid-19, responsable de la pandemia, constituye la mayor crisis de la salud publica en todo el mundo, con cerca de 34 millones de infectados y más de 1 millón de fallecidos hasta fines de setiembre del presente $^{(1)}$.

Desde los primeros reportes de la provincia de Wuhan en China, la población con mayor morbi mortalidad fueron la de los adultos mayores y las personas con enfermedades de base. En Paraguay el primer caso se registró en el mes de marzo en un adulto y semanas después se reportan los primeros casos en la población pediátrica, en relación con contactos familiares. Con el aumento de la circulación viral, los casos pediátricos fueron incrementándose en forma gradual, y a un ritmo muy inferior al observado en la población adulta. Los primeros infectados fueron adolescentes y recién cuando el virus se extendió ampliamente en la comunidad fueron afectados los de menor edad. Hasta el 19 de setiembre del presente, de acuerdo a los datos de la Dirección General de vigilancia de la salud (DGVS) del Ministerio de Salud Pública del país, el 6,9\% (2268) de los infectados por el SARS CoV fueron niños asintomáticos o con cuadros leves. El porcentaje de hospitalización fue del 2,9\% y 3 pacientes fallecieron $(0,13 \%)$. Estos datos son similares a los reportados en varios paises desde el inicio de la pandemia ${ }^{(2-4)}$. Los resultados de la primera revisión sistemática que incluyo 45 estudios, indica que entre el 1 al 5\% de la población diagnostica con SARS CoV-2 positivo son niños, la mayoría fueron casos leves con mejor evolución que la observada en adultos y la mortalidad muy baja ${ }^{(5)}$. En este número de la revista, Morilla y cols. reportan la primera serie de casos pediátricos de Covid-19 en el país, en un hospital pediátrico de referencia. El $48 \%$ fueron manejados en forma ambulatoria, más del tercio de los pacientes eran menores de 2 años, el 32\% tenían alguna comorbilidad y el cuadro clínico predominante fue de infección de vías aéreas superiores seguido de neumonía.

Por lo general las infecciones virales son más frecuentes y severas en la población pediátrica, sobre todo en los menores de 1 año. La menor afectación y severidad de la Covid-19 en la población pediátrica, planteo la interrogante sobre la susceptibilidad de los niños al SARS CoV2. Se ha intentado explicar recurriendo a los conocimientos actuales sobre el sistema inmunitario del niño. Es posible que el entrenamiento de la inmunidad innata en esta población, debido a las vacunas recibidas, generalmente a virus vivos y a los frecuentes cuadros virales, en la primera infancia pudieran producir cambios epigéneticos en las células inflamatorias responsables de la respuesta al virus $^{(6)}$. El otro aspecto considerado es la inmunidad cruzada con otros grupos de coronavirus, causa común de infecciones de las vías aéreas superiores en los niños. Es posible que induzca al desarrollo de

\footnotetext{
${ }^{1}$ Hospital General Pediátrico “Niños de Acosta Nu”. San Lorenzo, Paraguay.

Correspondencia: Mirta Mesquita Correo:mirtanmr@gmail.com

Recibido: 01/06/2020 Aceptado:06/10/2020

Doi: https://doi.org/10.31698/ped.47032020001
}

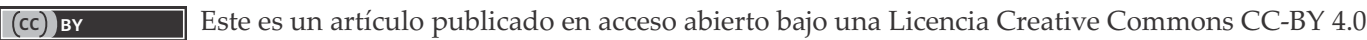


anticuerpos protectores contra otros coronavirus como el SARS CoV-2 ${ }^{(7)}$. Un metaanálisis reciente que incluyo 32 estudios concluyo que los niños y adolescentes tienen menor susceptibilidad de contagiarse ante un contacto que los adultos con una OR de 0,56 . $^{(8)}$

El rol de la Enzima Convertidora de Angiotensiva (ACE-2 por sus siglas en inglés) fue motivo de numerosos estudios, tratando de comprender la fisiopatología de la enfermedad causada por este novel virus. El SARS CoV-2 ingresa a las células, principalmente en los neumocitos tipo2 por medio de los receptores de esta enzima. Su relación con la menor susceptibilidad del niño al SARS CoV-2 pudiera ser explicado por el menor desarrollo de estos receptores en las células pulmonares del niño. Del mismo modo la menor severidad de los cuadros pudiera explicarse en parte por la gran actividad de esta enzima en los niños a favor de la angiotensina 2 con efecto antiinflamatorio ${ }^{(9)}$.

Sin duda los mediadores de la inflamación cumplen un papel importante en la interacción entre el niño y el SARS CoV. Un ejemplo de ello es el denominado síndrome inflamatorio multisistémico (MIS-C por sus siglas en ingles), caracterizado por marcada inflamación multisistémica, con afectación multiorgánica, vasculitis, que puede presentarse como un schock toxico. Tiene alguna similitud con la Enfermedad de Kawasaki. Se presenta en niños y adolescentes 2 a 4 semanas después de la infección ${ }^{(10)}$. No está muy claro el rol de los niños en la transmisión de la Covid-19. De acuerdo con los primeros reportes se los consideraba como grandes transmisores, con prolongada excreción del virus confirmado por test positivos hasta por 2 semanas aun en los casos leves o asintomáticos. Es posible que sean un medio importante de transmisión en la familia, considerando que no tienen actividades fuera de la casa. Sin embargo, es un tema que amerita más estudios, sobre todo en relación a la excreción prolongada del virus o parte de la proteína viral, y su capacidad de infectar ${ }^{(11)}$.

No hay evidencias irrefutables de la transmisión vertical de la madre al feto ${ }^{(12)}$. Sin embargo, la transmisión perinatal, durante el parto, periodo neonatal inmediato y posterior es posible. Y también evitable con estrictas medidas higiénicas y constituye la base de la recomendación de no separar a las madres positivas de sus neonatos y la alimentación con leche materna ${ }^{(13)}$.

A pesar de llevar más de 7 meses de pandemia, y del esfuerzo de la comunidad científica mundial, hay enormes brechas en el conocimiento del comportamiento del virus, que dificulta tener herramientas terapéuticas y de prevención efectivas. Por otra parte, hay miles de publicaciones, al alcance de todos los profesionales por la liberación de las revistas, aun las de gran impacto. Muchas están disponibles antes de la revisión por pares, situación que obliga a afinar la capacidad de distinguir el trigo de la paja. Después de todo "la ausencia de evidencia no es evidencia de ausencia"

Mas allá de la menor susceptibilidad de la Covid-19, y la menor morbimortalidad, los niños son los grandes perdedores de esta pandemia. Con la cuarentena, miles de niños preescolares y escolares iniciales, no aprendieron a leer, a escribir, a realizar operaciones de matemáticas ni a socializar. En las ciudades, posiblemente los niños mayores, se volvieron adictos a los teléfonos celulares o videos juegos, mientras que en la población rural y con niveles socioeconómicos más bajos, simplemente están viendo irse un año, que no solo afecto la economía familiar, sino también sus capacidades de desarrollar, aunque sea un esbozo de pensamiento lógico y de comprensión lectora. 


\section{REFERENCIAS}

1. Dong E, Du H, Gardner L. An interactive web-based dashboard to track COVID-19 in real time. Lancet Inf Dis. 2020; 20(5):533-534. doi: http://dx.doi.org/10.1016/S14733099(20)30120-1

2. Dirección General de Vigilancia de la Salud; Ministerio de Salud Pública y Bienestar Social. Vigilancia de Covid-19 en Pediatría [Internet]. Paraguay: Dirección del Centro de Información Epidemiológica; 2020 [Citado 30 Set. 2020]. Disponible en: http://www.vigisalud.gov.py/files/ boletines_covid19/SE38_2_2020_Boletin_Covid19.pdf

3. Dong $\mathrm{Y}, \mathrm{Mo}$ X, Hu Y, Qi X, Jiang F, Jiang Z, et al. Epidemiology of COVID-19 Among Children in China. Pediatrics. 2020;145(6):e20200702. doi: http://dx.doi.org/ 10.1542/peds.2020-0702.

4. Lu X, Zhang L, Du H, Zhang J, Li YY, Qu J, et al. SARSCoV-2 Infection in Children. N Engl J Med. 2020;382(17):16631665. doi: http://dx.doi.org/10.1056/NEJMc2005073

5. Ludvigsson JF. Systematic review of COVID-19 in children shows milder cases and a better prognosis than adults. Acta Paediatr. 2020;109(6):1088-1095. doi: http://dx.doi.org/10.1111/apa.15270

6. Yuan M, Wu NC, Zhu X. A highly conserved cryptic epitope in the receptor-binding domains of SARS-CoV-2 and SARS-CoV. Science. 2020:eabb7269. doi: http://dx.doi.org/10.1126/science.abb7269

7. Nankabirwa V, Tumwine JK, Mugaba PM, Tylleskär T, Sommerfelt H; PROMISE- EBF Study Group. Child survival and BCG vaccination: a community based prospective cohort study in Uganda. BMC Public Health. 2015;15:175. doi: http://dx.doi.org/10.1186/s12889-015-1497-8
8. Viner RM, Mytton OT, Bonell C, Melendez-Torres GJ, Ward J, Hudson L, et al. Susceptibility to SARS-CoV-2 Infection Among Children and Adolescents Compared With Adults: A Systematic Review and Meta-analysis. JAMA Pediatr. 2020; Online ahead of print. doi: http://dx.doi.org/10.1001/jamapediatrics.2020.4573

9. Brielle ES, Schneidman-Duhovny D, Linial M. The SARS-CoV-2 Exerts a Distinctive Strategy for Interacting with the ACE2 Human Receptor. Viruses. 2020;12(5):497. doi: http://dx.doi.org/10.3390/v12050497

10. Belhadjer Z, Méot M, Bajolle F, Khraiche D, Legendre A, Abakka S, et al. Acute heart failure in multisystem inflammatory syndrome in children (MIS-C) in the context of global SARS-CoV-2 pandemic. Circulation. 2020; Online ahead of print. doi: http://dx.doi.org/10.1161/CIRCULA TIONAHA.120.048360

11. Cao Q, Chen YC, Chen CL, Chiu CH. SARS-CoV-2 infection in children: Transmission dynamics and clinical characteristics. J Formos Med Assoc. 2020;119(3):670-673. doi: http://dx.doi.org/10.1016/j.jfma.2020.02.009

12. Marzollo R, Aversa S, Prefumo F, Saccani B, Perez CR, Sartori E, et al. Possible Coronavirus Disease 2019 Pandemic and Pregnancy: Vertical Transmission Is Not Excluded. Pediatr Infect Dis J. 2020;39(9):e261-e262. doi: http://dx.doi.org/10.1097/INF.0000000000002816

13. WHO. Breastfeeding and World Health COVID-19: scientific brief. WHO; 2020 [Citado 4 Ago. 2020]. Disponible en: https://www.who.int/publications/i/item /10665332639 